Check for updates

The BMJ

Cite this as: BMJ2020;371:m4254 http://dx.doi.org/10.1136/bmi.m4254 Published: 02 November 2020

\section{Covid-19: Experts question evidence behind prime minister's promise of rapid tests}

\section{Elisabeth Mahase}

Concerns have been raised over the UK government's claims that it will begin rolling out rapid covid-19 tests within days to whole cities to "help people discover whether or not they are infectious" and to allow them entry to certain places or events.

Announcing the second national lockdown in England on 31 October, ${ }^{1}$ Boris Johnson said that trials of rapid tests across the country in schools and hospitals had shown that they "drive down the disease." As a result, millions of these self-administered tests, which provide results in 10-15 minutes, will now be rolled out "over the next few days and weeks."

Johnson added that the tests would be used in an "ever growing number of situations," including to allow partners of women giving birth to be in labour wards.

He did not name the test to be rolled out, and although three rapid antigen tests have passed Public Health England's assessment there is little information on how they were tested or passed. ${ }^{2}$

One of these tests has since been purchased. The Telegraph reported that the government agreed a deal for 20 million of Innova's SARS-CoV-2 antigen test kits on 19 October. ${ }^{3}$ The test involves a nose and throat swab and provides results similar to an at-home pregnancy test. However, the company's instructions state that the test is intended only for use on people showing symptoms of covid-19 and should be used by "clinical laboratory personnel specifically instructed and trained in the techniques of in vitro diagnostic procedures." As such, this test would not be suitable for testing asymptomatic people to allow access, as Johnson had claimed.

Jon Deeks, professor of biostatistics at the University of Birmingham and lead author of a recent Cochrane review of covid-19 antibody tests, has also raised concerns over Public Health England's test assessments. ${ }^{4}$ He said, "These are initial validation studies and should not be the basis for national decision making ... Boris [Johnson] described these as tests of whether you are infectious, but there is no mention of infectiousness in the protocol; they are assessed as tests of infection not infectiousness."

Simon Clarke, associate professor of cellular microbiology at the University of Reading, said that Johnson's testing announcement seemed hurried and may have been done "purely as a way to provide some sugar along with the bitter medicine of lockdown." Nevertheless, he said that "mass rapid and effective testing and isolating of infected people really is the best way for the country to get out of this nightmare," although the details on how this would be achieved were still "thin on the ground."
He added, "We will need to see some serious concrete plans, and quickly, if we are not to suspect that the prime minister's statement was purely about news management."

\section{Appointments challenged}

The government is also facing criticism over how it appoints people to key public sector roles during the pandemic. In a legal challenge the Good Law Project and Runnymede Trust have joined forces to put forward the case that people who were personally or politically connected with senior members of the Conservative Party have been appointed without any open competition or proper process. This was indirect discrimination (contrary to the Equality Act 2010), they said, and a breach of the public sector equality duty.

Dido Harding, appointed head of the NHS Test and Trace service and then interim head of the National Institute for Health Protection, is named in the claim. She is married to the Conservative MP John Penrose.

Mike Coupe, Gareth Williams, Ben Stimson, and Paul de Laat, all appointed to senior positions at NHS Test and Trace, have also been named. Coupe is the former chief executive officer of Sainsbury's and a former colleague and friend of Harding from their time at Sainsbury's, said the Good Law Project and Runnymede Trust.

Halima Begum, the trust's director, said, "When a recruitment process is not open and fair, it discriminates against those who are not already connected to the decision makers. This has a serious detrimental impact on equality and on the diversity of the people at the top of organisations who get to call the shots. This is always important, but even more so now so many lives depend on it, and particularly as we know black and Asian people continue to be disproportionately affected by the coronavirus.

"We are calling on the government to ensure a proper process is followed and for NHS bodies to be truly representative of the people they protect."

Kmietowicz Z. Covid-19: “There is no alternative," says Johnson, announcing new restrictions for England. BMJ2020;371:m4247.

2 Department of Health and Social Care. Protocol for evaluation of rapid diagnostic assays for specific SARS-CoV-2 antigens (lateral flow devices). 23 Oct 2020. https://www.gov.uk/government/publications/assessmentand-procurement-of-coronavirus-covid-19-tests/lateral-flow-devices-results\#test-2-innova-sars-cov-2-antigen-test.

Bodkin H, Mendick R. Government secures up to 20 million 15-minute covid test kits. Telegraph. 19 Oct 2020. https://www.tele-

graph.co.uk/news/2020/10/19/government-secures-20-million-covid-quicktesting-kits.

Deeks J. Twitter. 1 Nov 2020. https://twitter.com/deeksj/status/1323004129350946822. 